\title{
La SCPH — un organisme de bénévoles
}

\author{
par Bruce Millin
}

$\mathrm{L}$ Société canadienne des pharmaciens d'hôpitaux (SCPH) s'est dotée d'un nouveau plan stratégique qui la guidera jusqu'en 2018. La mobilisation des membres et des bénévoles est l'un des champs stratégiques clés du plan, dont l'un des buts stratégiques est la mise sur pied d'un réseau florissant de bénévoles. Au début d'avril 2016, alors que je rédigeais l'ébauche de ce commentaire, approchait la Semaine de l'action bénévole (du 10 au 16 avril), qui met les bénévoles à l'avant-plan. Cette semaine sert à souligner officiellement l'engagement des bénévoles du pays et le temps qu'ils consacrent aux organismes de leur choix.

En termes simples, sans eux la SCPH n'existerait pas. Outre l'excellent travail de la petite équipe de salariées dévouées à notre siège social d'Ottawa, la majorité de ce que la SCPH accomplit en ce qui touche à la valorisation, au perfectionnement professionnel, à la promotion des meilleures pratiques, à l'appui à la recherche et à la reconnaissance de l'excellence ne pourrait voir le jour sans l'action concertée des bénévoles. Pour cette raison, la SCPH n'est pas seulement un organisme à adhésion volontaire, mais aussi un organisme de volontaires.

L'une des façons d'établir un réseau florissant de bénévoles est de montrer à ceux-ci que leur temps et leur dévouement font avancer les choses. Le projet SCPH 2015 pour l'excellence en pratique a été une réussite justement parce que les bénévoles qui y ont travaillé ont vu l'influence importante que leurs efforts avaient sur les pharmaciens quotidiennement. On espère que le nouveau projet de la SCPH orienté vers l'amélioration des résultats cliniques aura un effet semblable sur les bénévoles qui ont manifesté le désir de faire progresser cette stratégie pour l'excellence en pratique.

Un autre atout pour un réseau florissant de bénévoles est de montrer que chacun peut jouer un rôle important. Qu'il ne s'agisse que d'un simple coup de main ou d'un peu de temps, chaque contribution fait avancer les choses pour la personne et l'organisme.

Le bénévolat est un apprentissage qui offre aux individus une excellente occasion de développer leurs aptitudes en leadership. Les leçons tirées en siégeant comme président ou comme membre d'un groupe de travail ou d'un comité peuvent aussi servir dans le milieu de travail. Des collègues me demandent souvent de leur conseiller des moyens, autres que des cours, pour développer leurs aptitudes en leadership. Je les encourage toujours à participer aux comités de la SCPH pour développer certaines de leurs aptitudes. Une telle expérience offre un avantage supplémentaire : elle facilite la planification de la relève tant pour la SCPH que pour les établissements.

La Semaine canadienne de l'action bénévole sert à attirer l'attention du pays sur les bénévoles, mais il ne faut pas souligner leur dévouement seulement une fois par année. Il faut continuellement manifester sa reconnaissance et, pour cela, un événement formel n'est pas nécessaire. Un simple « merci " peut représenter beaucoup.

Donc, au nom de la direction de la SCPH, je souhaite dire un grand merci à tous les bénévoles pour leur travail précieux!

[Traduction par l'éditeur]

Bruce Millin, B. Sc. (Pharm.), ACPR, est président sortant et agent de liaison interne pour la Société canadienne des pharmaciens d'hôpitaux. 